\title{
HERBAL DRUG-INDUCED ADVERSE DRUG REACTION: A CASE REPORT
}

\author{
MANJU GARI, LAKHAN MAJHEE ${ }^{1}$, KAVITA KUMARI ${ }^{2 *}$
}

Department of Pharmacology, Rajendra Institute of Medical Sciences, Ranchi, Jharkhand, India. Email: kavitapandey681@gmail.com*

Received: 24 August 2017, Revised and Accepted: 16 November 2017

\begin{abstract}
The present study done to focus many adverse drug reactions unrecorded with either patients failing to present to health services due to herbal medicine or no pharmacovigilance analysis is being made. In this case, a 55-year-old female patient with $41 \mathrm{~kg}$ weight, she received herbal treatment for gastritis and menstrual disturbance since November 2015. After administration of drug, she suddenly developed 23 small vesicles over neck and upper chest. Few vesicles ruptured over 4-5 days and few gradually increased in size to form bulla. The use of herbal drug has increased tremendously across the world in recent times. Hence, it has become important for pharmacovigilance of herbal drugs and adverse effect issues for the consumers and health-care professionals as it is complex to analyze these products than the conventional pharmaceuticals. "Safe" and "natural" cannot be used anonymously. Sufficient adverse drug monitoring of herbal drugs is as important as any other formularies.
\end{abstract}

Keywords: Vesicles, Pharmacovigilance, Herbal drug, Adverse drug reaction.

(C) 2018 The Authors. Published by Innovare Academic Sciences Pvt Ltd. This is an open access article under the CC BY license (http://creativecommons. org/licenses/by/4. 0/) DOI: http://dx.doi.org/10.22159/ajpcr.2018.v11i2.22208

\section{INTRODUCTION}

Herbal drugs include plants and plant material which use for the promotion of healing and maintenance of health-related problems. The trend for use of herbal medicines originated in Egypt back in $1550 \mathrm{BC}$ [1]. About $80 \%$ of the world population use some form herbal medicine and herb-related product. The use of herbal medicines is increasing day by day to avoid toxic effect of chemicals and they trust on natural products, its usage increases annually at a rate of $10-20 \%$ [2]. The safety of herbal medicines is necessary because the majority of these products is self-prescribed and is used to treat all types of conditions such as minor and chronic health-related problems. Most patient consuming herbal preparations are not aware of the potential. Adverse effects of these preparations may produce. They do not have the knowledge of herbal constituents and its risk. The number of adverse effects of herbal medicines is now increasing in the study of pharmacovigilance. Herbal drug-induced adverse effect cases also increased due to increased use of herbals and also probably due to increased awareness among the consumers and clinical practitioners [3]. The awareness of the environmental damage caused by industrialization, containing chemicals, a trend has developed to use products of natural ingredients [4]. Herbal supplements become more popular after several adverse effects have been reported by the users who take other medications and chemicals [5]. Directly or indirectly $60 \%$ of conventional medicines on the global market derived from natural products, including herbs [6]. This belief is augmented by many other unwarranted claims such as herbal products do not contain chemicals while conventional medicines do, thus contributing to the latter's side effects. From the awareness about pharmacovigilance analysis and clinicians, many cases of herbal drug reaction reported $[7,8]$.

\section{CASE REPORT}

A 55-year-old female patient with $41 \mathrm{~kg}$ weight, she took herbal (ayurvedic) treatment by local doctor for gastritis and menstrual disturbance. She purchased drugs from Patanjali store which content details available in Table 1 and administered by oral route 1 time in a day since November 2015. After administration of drug, she suddenly developed 2-3 small vesicles over neck and upper chest. The patient presented in the outpatient department of Dermatology Department at Rajendra Institute of Medical Sciences (RIMS) hospital, Ranchi,
Jharkhand, with the complaints of multiple fluid lesions all over the body for the past 6 months, and she was admitted in hospital on October 19, 2016 in the Department of Dermatology of RIMS, Ranchi. The vesicles then appeared on face, oral mucosa, on exterior surface of upper limb, abdomen, lower limbs, scalp, and genital. Few vesicles ruptured over 4-5 days, few gradually increased to form bulla which shown in (Figs. 1, 2). The vesicles were associated with itching and burning sensation. There is no fever during eruption of vesicles. History revealed that patient was operated for dermoid cyst in gluteal region in September 2016. Clinician diagnosed that patient has symptoms of pemphigus vulgaris. The herbal drug details shown in (Figs 3,4), which withdrawn after the reaction and admitted on the same day (October 18, 2016), patient also had been taken aloe vera juice as concomitant medication. She developed mouth ulcer, constipation during treatment of reaction. She has given proper treatment by skin department with Capsule Hikal Z, Oinment. Megaheal, Tablet Wysolone, Lotion Gention violet Solution, etc. Other skin investigation was done. She admitted in hospital from October 19, 2016, to December 6, 2016, for proper care and treatment, her reaction was in recovering condition. She has been discharged on December 6, 2016. It was suspected that the adverse events were related to the suspected drug and causality assessment (as per WHO-Causality Scale) was possible. This case was observed under Pharmacovigilance Programme of India which is running at Department of Pharmacology, RIMS, Ranchi. Patient's cutaneous examination and lab investigation shown in Table 2-3.

\section{DISCUSSION}

Use of herbal drug has increased tremendously across the world in recent times [9]. The main reason behind is the belief that it is good for healthy living, without any adverse reaction. People have belief for herbal drug due to lack of good quality control, inadequate labelling and proper information [10]. Hence, it has become important in pharmacovigilance of herbal drugs and adverse effect issues for the consumers and health-care professionals as it is complex to analyze these products than the conventional pharmaceuticals [11,12]. Pharmacovigilance of herbal drug become highlighted after reporting of some cases as ; multiple follicular development associated with herbal medicine [13]. Fessenden et al. A case report of herbal medicine and bleeding postoperatively from a laparoscopic cholecystectomy [14]. 
Table 1: Drug details

\begin{tabular}{lll}
\hline Drug & Contents & Dose \\
\hline Herbal drug & $\begin{array}{l}\text { Bryonia laciniosa -34 mg/Thespesia } \\
\text { populnea 34 mg/Mesna ferra 34 mg/ }\end{array}$ & $500 \mathrm{mg}$ \\
& Withania somnifera 34 mg/Tephrosia & \\
& purpurea 34 mg/Asparagus racemosus & \\
& 34 mg/Glycyrrhiza glabra 34 mg/Emblica \\
& officinalis 34 mg/Cedrus deodara 34 & \\
& mg/Nelumbo nucifera 34 mg/Putranjiva & \\
& roxburghii 34 mg/Bombusa 34 mg/ \\
& $\begin{array}{l}\text { Commiphora mukul 34 mg/Lauh bhasma } \\
\text { 34 mg carbonate/Coriandrum }\end{array}$ & $500 \mathrm{mg}$ \\
& $\begin{array}{l}\text { Potassium } \\
\text { sativum/Cinnamomum verum/Tinospora } \\
\end{array}$ & \\
\hline
\end{tabular}

Table 2: Cutaneous examination

\begin{tabular}{|c|c|}
\hline Scalp & $\begin{array}{l}\text { Mild seborrhea present, ruptured bulla, well } \\
\text { defined, irregular in shape present over scalp }\end{array}$ \\
\hline Face and neck & $\begin{array}{l}\text { Multiple vesicles and bulla of variable size } \\
\text { present over the cheek, nose and jaw, also } \\
\text { on neck, the bulla was flaccid, Few bulla is } \\
\text { ruptured, increase serous discharge }\end{array}$ \\
\hline $\begin{array}{l}\text { Chest and } \\
\text { abdomen }\end{array}$ & $\begin{array}{l}\text { Similar lesions are present over the hands in } \\
\text { the axillaries region }\end{array}$ \\
\hline $\begin{array}{l}\text { Back, upper limb, } \\
\text { Lower limb }\end{array}$ & $\begin{array}{l}\text { Similar lesions are present over the back, } \\
\text { exterior surface of upper limb, over elbow, } \\
\text { back of arm, exterior surface of lower limb, } \\
\text { over knee joint. }\end{array}$ \\
\hline Palms and soles & Not involved \\
\hline Nails & Not involved \\
\hline Mucosa & $\begin{array}{l}\text { Conjunctive - normal } \\
\text { Oral mucosa - multiple vesicles present over } \\
\text { buccal mucosa of variable shape and size, } \\
\text { vesicles are ruptured } \\
\text { Genitals - multiple vesicles are present over } \\
\text { the labia majora, ruptured, increase serous } \\
\text { discharges }\end{array}$ \\
\hline
\end{tabular}

Table 3: Laboratory investigation

\begin{tabular}{ll}
\hline Date & Test \\
\hline $20 / 08 / 2016$ & $\begin{array}{l}15 \mathrm{~cm} \times 12 \mathrm{~cm} \text { cyst in sacral and perineal area with } \\
\text { erythematous overlying skin }\end{array}$ \\
17/09/2016 & $\begin{array}{l}\text { Histopathology report: Dermoid cyst with } \\
\text { secondary inflammation }\end{array}$ \\
& Hgb $-10.2 \mathrm{~g} / \mathrm{dl}, \mathrm{HCT}-33.4 \%, \mathrm{MCHC}-30.5 \mathrm{~g} / \mathrm{dl}$ \\
\hline
\end{tabular}

Hgb: Hemoglobin, MCHC: Mean corpuscular hemoglobin concentration, HCT: Hematocrit

A large number of Americans are using herbal products for preventive and therapeutic purposes [15]. The inclusion of herbal medicines in pharmacovigilance systems is becoming increasingly important given the growing use of herbal products and herbal medicines globally. For example, in the United States of America, some US $\$ 17$ billion was spent by more than 158 million Americans in 2000. Further, under the recent study indicated that more than $70 \%$ of the German population reported using "natural medicines" and that, for most of them, herbal medicinal products were the first choice in the treatment of minor diseases or disorders. The worldwide consumption of herbal medicinesis enormous, so that, in terms of population exposure alone, it is essential to identify the risks associated with their use [9]. The manufacturers of herbals products are not required to submit proof of safety and efficacy to the U.S. regulatory agency (FDA) before marketing of herbals so the adverse effects of herbal remedies are largely unknown and unclear [15]. A time

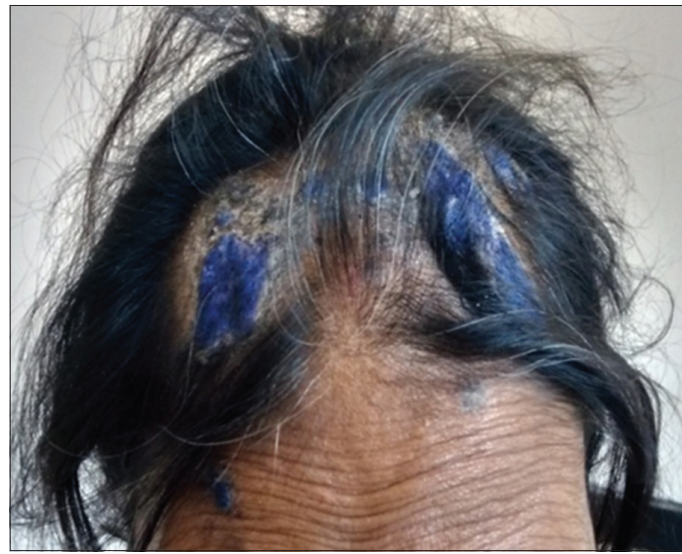

Fig.1: Raptured bulla

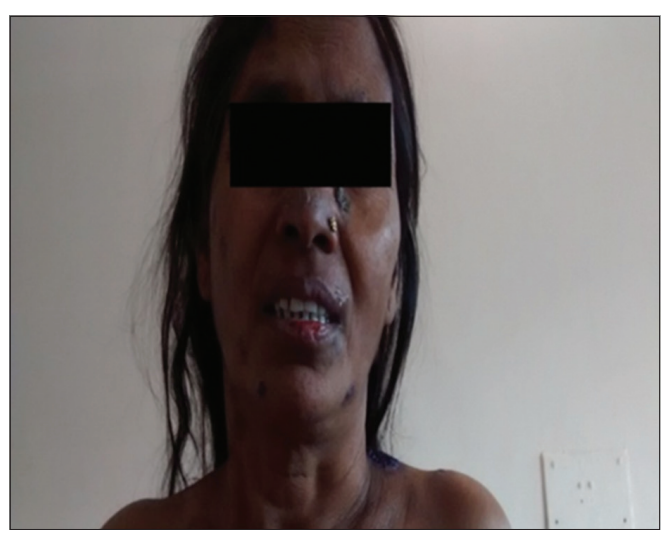

Fig. 2: Multiple Fluid Lesions

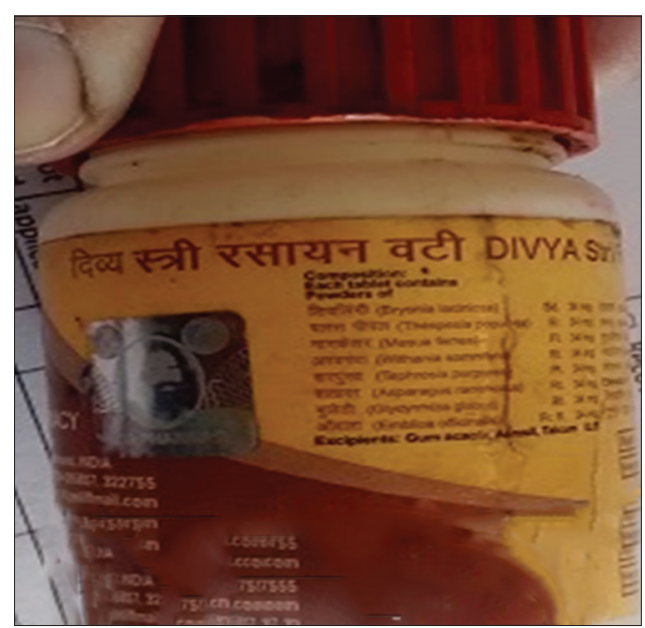

Fig. 3: Herbal drug 1

has come to make a strict policies to strengthen and standardization of herbal drugs. Physicians must be alert for the adverse effects associated with herbal remedies [15]. Physicians need to emphasize that many pharmaceuticals were originally derived from plant products and that herbal remedies can be as potent as pharmaceuticals. Physicians need to ask specific questions regarding the use of vitamins, minerals, herbs or other botanicals, amino acids, concentrates, metabolites, extracts, and any other dietary substances being used by their patients. They should also obtain information about directions for use, methods of preparation, and dosage formulations [16]. Safety of herbal medicines is therefore an important public health issue. Herbal medicines are frequently used in conjunction with other medicines, and it is essential 


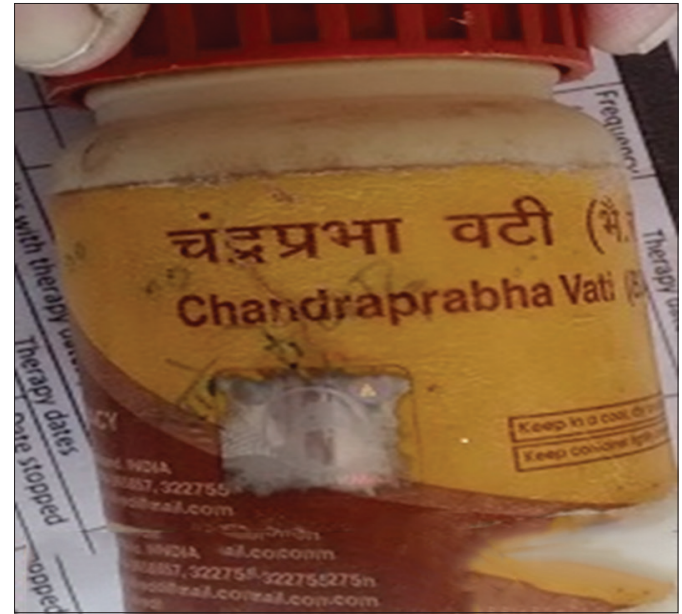

Fig. 4: Herbal drug 2

to understand the consequences of such combined use and monitor whether any adverse effects are arising. This can be achieved most readily within existing pharmacovigilance systems [9]. The problem of adverse reaction due to herbal drugs can be minimized by taking several complementary actions as clear identification of the nature of adverse events, management of the risks, institution of measure to prevent adverse events, good communication of the risks, and benefits of herbal medicines.

\section{CONCLUSION}

"Safe" and "natural" cannot be used anonymously. Sufficient adverse drug monitoring of herbal drugs is as important as any other formularies. It has become important for pharmacovigilance of herbal drugs and adverse effect issues for the consumers and health-care professionals.

\section{ACKNOWLEDGMENT}

The authors would like to thank the Pharmacovigilance Programme of India, running under Indian Pharmacopoeia Commission (IPC). This case has been sent to IPC and we are grateful to IPC for allowing us to publish this case.

\section{REFERENCES}

1. von Reis Altschul S. Exploring the herbarium. Sci Am 1977;236:96-104.

2. Phillipson JD, Chan KL, Hussin AH, Sadikun A, Yuen KH, Asmawi MZ, et al., editors. Global Trend and Market Size of Herbal Medicine in Primary Health Care: Trends in Traditional Medicine Research. Penang: Universiti Sains Malaysia; 1995.

3. Abas HH. Adverse effects of herbs and drug-herbal interactions. School of pharmaceutical sciences. Universiti Sains Malaysia. 11800 Pulau Pinang, Malaysia. Malays J Pharm 2001;1:39-44.

4. Vender RB. Adverse reactions to herbal therapy in dermatology. Skin Therapy Lett 2003;8:5-8

5. Neldner KH. Complementary and alternative medi-cine. Dermatol Clin 2000;18:189-93.

6. Ji HF, Li XJ, Zhang HY. Natural products and drug discovery. Can thousands of years of ancient medical knowledge lead us to new and powerful drug combinations in the fight against cancer and dementia? EMBO Rep 2009;10:194-200.

7. Paul AM, Antony A, Nu S, Hameed H. A case report on ayurvedic medicine (Red mercuric sulphate) induced bronchioli tis obliterans organizing pneumonia (boop) in sero positive rheumatoid patient. Int $\mathbf{J}$ Pharm Pharm Sci 2015;7:300-401.

8. Rajasekar GS, Brindha P, Ramanathan V. Effective management of hemolytic complications by traditionally prepared Kantam formulations. Int J Pharm Pharm Sci 2017;9:27-34

9. WHO Guidelines on Safety Monitoring of Herbal Medicines in Pharmacovigilance Systems. Geneva, Switzerland: World Health Organization; 2004. p. 1-3.

10. Raynor DK, Dickinson R, Knapp P, Long AF, Nicolson DJ. Buyer beware? Does the information provided with herbal products available over the counter enable safe use? BMC Med 2011;9:94.

11. WHO. National Policy on Traditional Medicine and Regulation of Herbal Medicines. Report of a World Health Organization Global Survey. Geneva, Switzerland: WHO; 2005b.

12. Zhou J, Ouedraogo M, Qu F, Duez P. Potential genotoxicity of traditional Chinese medicinal plants and phytochemicals: An overview. Phytother Res 2013;27:1745-55.

13. Cahill DJ, Fox R, Wardle PG, Harlow CR. Case report: Multiple follicular development associated with herbal medicine. Hum Reprod 1994;9:1469-70.

14. Fessenden JM, Wittenborn W, Clarke L, Biloba G. A case report of herbal medicine and bleeding postoperatively from a laparoscopic cholecystectomy. Am Surg 2001;67:33.

15. Melanie JC, Herbal Remedies: Adverse Effects and Drug interactions. American family physician Mar 1999;1;59(5):1239-1244

16. Richard K. Adverse reactions to watch for in patients using herbal remedies. West J Med 1999;171:181-6. 